\title{
LIX. On the method of transmission of the excited activity of radium to the cathode
}

\author{
Walter Makower B.A. B.Sc.
}

To cite this article: Walter Makower B.A. B.Sc. (1905) LIX. On the method of transmission of the excited activity of radium to the cathode, Philosophical Magazine Series 6, 10:59, 526-532, DOI: $10.1080 / 14786440509463400$

To link to this article: http://dx.doi.org/10.1080/14786440509463400

曲 Published online: 16 Apr 2009.

Submit your article to this journal $\lceil\pi$

Џ Article views: 3

Q View related articles $\square$

Citing articles: 1 View citing articles 5 
IIX. On the Method of Transmission of the Excited Activity of Radium to the Cathode. By Walter Makower, B.A., B.Sc.; Joln Harling Research Fellow in the University of Manchester ${ }^{*}$.

\section{Introduction.}

T has been shown by Rutherford $\uparrow$ that when a negatively charged rod is exposed to the emanation from thorium in a closed ressel, the quantity of excited activity deposited upon the rod in a given time is independent of the pressure of the gas with which the emanation is mixed as long as this pressure exceeds a certain value, but that below this limit the quantity of excited activity deposited on the negative electrode diminishes, at first slowly, and then more rapidly, as the pressure of the gas is reduced.

This phenomenon gives reason to suppose that at the moment of its formation the excited activity is uncharged, and that it is only by some subsequent secondary action upon the gas in which it is produced that it acquires the positive charge in virtue of which it is carried to the negative electrode. It was with a view to investigating the nature of this secondary action that the present experiments were undertaken.

No experiments regarding this point seem as yet to bave been carried out with radium emanation ; for this reason, and on account of the rapid rate of decay of thorium emanation and the consequent inconvenience of working with this substance, radium emanation was employed in the present research.

The variation with pressure of the amount of excited activity deposited in a given time on a negatively charged rod when exposed to a constant quantity of emanation was carefully investigated, and it was found that at low pressure the excited activity deposited on the rod depended, not only on the pressure of the gas, but also on the distance between the positive and negative electrodes.

As the result of some preliminary experiments it was shown that the activity acquired by the rod was independent of the difierence of potential between the electrodes over a considerable range. In these experiments a potential-difference of about 60 volts was used throughout.

* Conmunicated by the Physical Society.

† Phil. Mag. [5] rol.'xlix. (1900). 
Transmission of Excited Actirity of Redium to Cathode. 527

2. Description of Apparatus.

The cylindrical metal ressel $V$ (fig. 1), which could be filled with emanation when desired, was connected to the

lig. 1 .

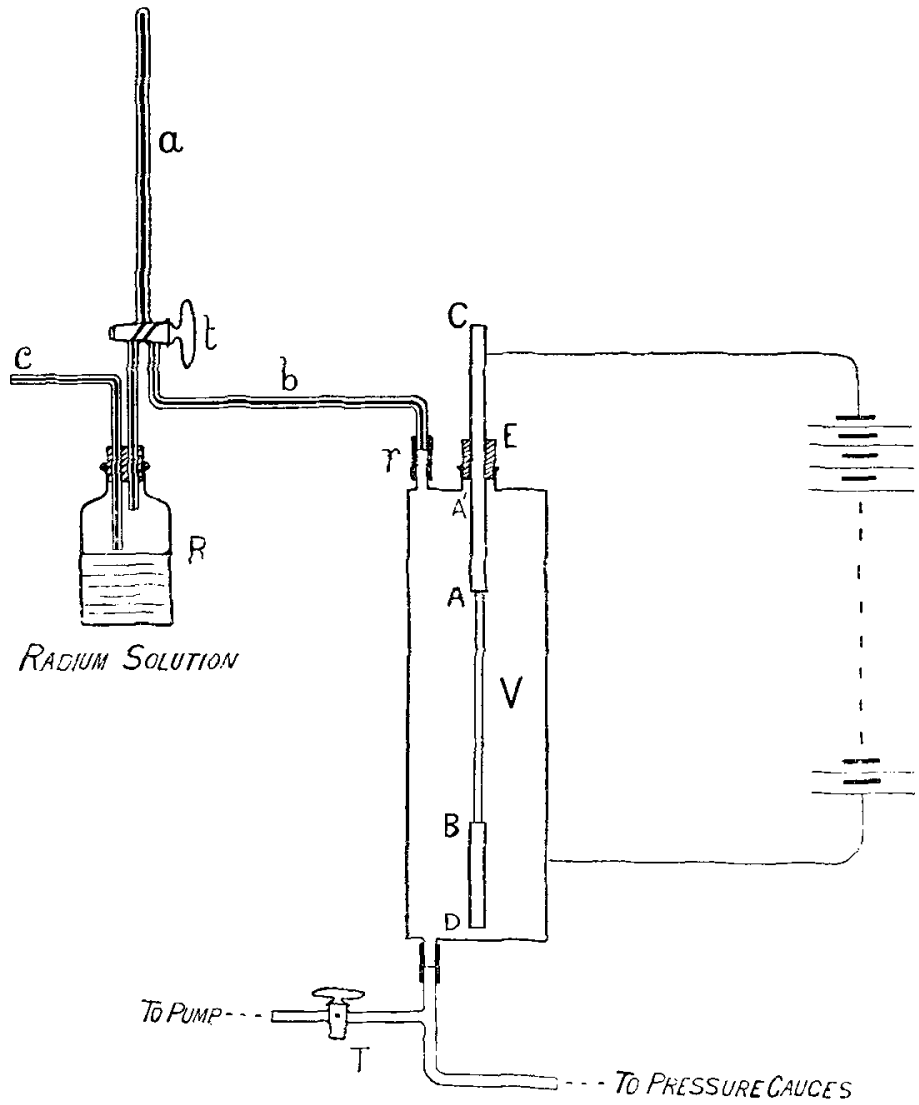

positive pole of a battery of thirty-small storage-cells. The wir $A B(14.5 \mathrm{~cm}$. long) was serewed into a stouter rod $\mathrm{AC}$ connected to ihe negative pole of the battery, and passing through a rubber stopper $E$ fitting air-tight into the neck of the vessel $\mathrm{V}$. The portion $\mathrm{AA}^{\prime}$ of the rod $\mathrm{AC}$ projected about $6 \mathrm{~cm}$. into the vessel $\mathrm{V}$, and another $\operatorname{rod} \mathrm{BD} 6 \mathrm{~cm}$. long was screwed to the lower extremity of $A B$, which was therefore exposed to a uniform electric field.

To obtain a constant supply of emanation, a strong solution of radium salt was placed in the glass bottle $\mathrm{R}$ provided with 
$528 \mathrm{Mr}$. W. Makower on the Method of Transmission

a stopper, through which passed a long capillary tube $\mathrm{C}$ reaching to the surface of the solution but not dipping into it.

The air inside $R$ was thus always kept at atmospheric pressure, and by making $\mathrm{C}$ sufficiently long the rate of escape of emanation from the bottle by diffusion was rendered small. After standing for some weeks, the concentration of the emanation in the air above the radium solution was found to have become sensibly constant.

To transfer a definite volume of gas from $\mathrm{R}$ into $\mathrm{V}$, the closed limb $a$ of the three-way capillary stopcock $t$ was connected by the capillary $b$ with the vessel $V$, to which it was attached by rubber $r$. By means of a pump the whole was exhausted to a low pressure, when the pump was disconnected by closing the tap T. The stopcock $t$ was then turned so as to connect $a$ with $\mathrm{R}$, allowed to stand for a short time and then again turned into its original position. In this way the volume $a$ (about 2 c.c.) of gas was transferred from $\mathbf{R}$ into $\mathrm{V}$, and by repeating the operation any required volume of emanation could be introduced into $\mathrm{V}$.

As the volume of $a$ was always small compared with that of $\mathrm{V}$. practically all the emanation in $a$ was discharged into $\mathrm{V}$ at low pressures; at higher pressures it was easy to apply a small correction for the quantity of emanation left in $a$.

The pressure in $\mathrm{V}$ was registered on a mercury manometer at the higher pressures, and on a McLeod gauge at the lower pressures.

The rod $\mathrm{AB}$ was exposed for 30 minutes to the emanation, and then transferred to another metal cylinder in which its activity was tested in the usual manner by means of a quadrant electrometer. As under these conditions the activity of the rod remains constant for about 10 minutes *, it was possible to take several observations of the activity, the means of which are recorded in Tables I., II., and III.

\section{Observations and Results.}

Experiments were performed with three vessels $V$ of diameter $1 \cdot 1 \mathrm{~cm}$. (vessel I.), $2 \cdot 6 \mathrm{~cm}$. (vessel II.), and $8 \cdot 3 \mathrm{~cm}$. (vessel III.) respectively. The pressure of the air with which the emauation was mixed was varied and the activity acquired by the rod in 30 minutes recorded.

With vessel I. it was found difficult to prevent the rod CD from touching the sides of the cylinder. The arrangement described above was therefore slightly modified by

* Miss Brooks, Phil. Mag. [6] vol. viii. p. 380 (1904). 
of the Eacited Activity of Radium to the Cathode. 529

making the cylinder $\mathrm{V}$ somewhat shorter and fixing the rod $B D$ into a rubber stopper fitting into the end of the cylinder.

In the case of vessel I. it was necessary to work with very small quantities of gas in order to get to sufficiently low pressures, and the capillary $a$ was discharged once into $V$. With vessels II. and III., $a$ was discharged twice and three times respectively.

The maximum value to which the activity deposited on $\mathrm{AB}$ tends at high pressures is not the same for the three vessels, on account of the difference in their dimensions and of the variation in the quantity of emanation used.

The results obtained are given in Tables I., II., and III., in which the pressures are given in cm. of mercury and the quantity of activity on the rod in arbitrary units.

\begin{tabular}{|c|c|}
\hline $\begin{array}{c}\text { Pressure } \\
\text { in cm. mercury. }\end{array}$ & $\begin{array}{l}\text { Activity } \\
\text { on rod. }\end{array}$ \\
\hline $15 \cdot 3$ & 180 \\
\hline $8 \cdot 9$ & 174 \\
\hline $6 \cdot 35$ & 167 \\
\hline $4 \cdot 3$ & 161 \\
\hline $2 \cdot 65$ & 134 \\
\hline $1 \cdot 7$ & 120 \\
\hline 0.95 & 93 \\
\hline \multicolumn{2}{|c|}{ Table II. (Vessel II.) diameter $2 \cdot 6 \mathrm{~cm}$} \\
\hline $\begin{array}{c}\text { Pressure } \\
\text { in } \mathbf{c m} \text {. mercury. }\end{array}$ & $\begin{array}{l}\text { Activity } \\
\text { on rod. }\end{array}$ \\
\hline $9 \cdot 3$ & 209 \\
\hline $8 \cdot 7$ & 219 \\
\hline $6 \cdot 2$ & 224 \\
\hline $5 \cdot 0$ & 214 \\
\hline $3 \cdot 3$ & $198 \cdot 5$ \\
\hline $2 \cdot 7$ & 183 \\
\hline $2 \cdot 6$ & 198 \\
\hline $2 \cdot 2$ & 191 \\
\hline $1 \cdot 7$ & 177 \\
\hline $1 \cdot 3$ & 182 \\
\hline 0.95 & 158 \\
\hline $0 \cdot 8$ & 150 \\
\hline $0 \cdot 44$ & 1.00 \\
\hline $0 \cdot 32$ & 87 \\
\hline $0 \cdot 12$ & 50 \\
\hline
\end{tabular}

Phil. Mag. S. 6. Vol. 10. No. 59. Nov. 1905. 
Tabie III. (Vessel III.) diameter $8 \cdot 3 \mathrm{~cm}$.

$\begin{array}{cc}\begin{array}{c}\text { Pressure } \\ \text { in cm. mercury. }\end{array} & \begin{array}{c}\text { Activity } \\ \text { on rod. }\end{array} \\ 5 \cdot 3 & 394 \\ 5 \cdot 15 & 410 \\ 4 \cdot 15 & 413 \\ 2 \cdot 0 & 409 \\ 1 \cdot 7 & 398 \\ 1 \cdot 4 & 385 \\ 1 \cdot 05 & 386 \\ 0 \cdot 8 & 367 \\ 0 \cdot 41 & 332 \\ 0 \cdot 38 & 346 \\ 0 \cdot 17 & 268 \\ 0 \cdot 10 & 178 \\ 0 \cdot 086 & 170\end{array}$

\section{Discussion of Results.}

The experiments described above show that, at low pressures, the excited activity produced from radium emanation contained in a closed vessel is not confined to the cathode, as in the case at high pressures, but is distributed over the walls of the containing vessels and appears both on the anode and cathode, even in a strong electric field. This is precisely what has been previously found with thorium emanation *, and shows that the method of transmission is probably the same.

It will be further noticed from the results given above that in a large vessel the influence of pressure on the concentration of the excited activity on the cathode becomes appreciable only at low pressures, whereas with smaller vessels this influence is noticeable at much higher pressures. If, therefore, we assume that at the moment of its production the excited activity is uncharged, it is evident that the proportion of particles of excited activity which can traverse the gas in which it is formed, and reach the anode without becoming charged, is a function of the length of its path through the gas. As has been pointed out by Rutherford $\dagger$, there are two ways in which the excited activity may be supposed to acquire a positive charge.

(1) The excited activity condenses on the positive ions existing in the gas and is thus transferred to the cathode; and

(2) The excited activity possesses the property of expelling

* Rutherford, loc. cit.

+ Rutherford, Phil. Mag. [6] vol. v. p.111 (1903). 
of the Eacited Artivity of Radium to the Cathode. 531

negatively charged particles, and so becomes positively charged.

To decide between these two hypotheses, Rutherford performed experiments in which the number of ions in the vessel containing the emanation was increased by external means, and found that the amount of activity deposited on a cathode in a given time was not increased by this means. For this reason he rejected hypothesis (1) in favour of (2).

The experiments were, however, carried out at atmospheric pressure; and it is possible that, under these conditions, the number of ions produced by the emanation is sufficiently great to remove the excited activity as fast as it is formed. in which case any further increase of the ionization would be without further effect. To test this point still further, some similar experiments have been made at a low pressure, using vessel III. The walls of the vessel were made the cathode and the central rod the anode; 20 volumes of the capillary $a$ (fig. 1 ) of emanation were introduced into the vessel and allowed to stand for $3 \frac{1}{4}$ hours, the pressure being atmospheric. The emanation was then completely pumped out as quickly as possible, and a new inactive rod $A B$ introduced and the field reversed. One volume of the capillary $a$ was then introduced into the vessel, and the rod exposed to the emanation at a pressure of $1 \mathrm{~mm}$. of mercury. Although the ionization in the vessel must have been increased about five times by the excited activity deposited on the walls of the vessel during the previous exposure to the emanation, the activity collected on the rod was found to be the same as when the walls were inactive. In a subsequent experiment 7 milligrams of pure radium bromide were brought close up to the vessel during the exposure of the negatively charged rod, without affecting the quantity of excited activity deposited on the cathode in 30 minutes. Supposition (2) is therefore the only one capable of explaining the observed phenomena.

It is of interest to speculate as to the mechanism by which a negatively charged particle is expelled from the excited activity during its passage through the gas. At the moment of formation of excited activity, the emanation from which it is produced expels an a particle * whereby the residue must itself be projected with considerable velocity. In their flight

* The negative charge left on the excited activity by the expulsion of an a particle may be neutralized by a simultaneous expulsion of slowlymoving electrons similar to those which Prof. J. J. Thounson (Proc. Camb. Phil. Soc. vol. xiii. part 1, p. 49) has shown to be given off by radio-tellurium. 
these particles of excited activity would collide with the molecules of the gas in which they are produced, and it is suggested that in a certain percentage of these collisions a negative particle is expelled, leaving the excited activity positively charged. To explain the results obtained in this investigation on this view, it is necessary to assume that the particles of excited activity, when mixed with air at $1 \mathrm{~cm}$. pressure, travel a distance comparable with $1 \mathrm{~cm}$. before becoming charged. This distance is great compared with the mean free path of a molecule of air at the same pressure, and therefore only a very small fraction of the collisions can be effective in causing a negative particle to be expelled by the excited activity.

I am indebted to Professor Schuster both for placing the resources of his laboratory at my disposal and also for much valuable criticism during the course of these experiments.

LX. Note on a Paper by W. Makower entitled "On the Method of Transmission of the Excited Activity of Radium to the Cathode." By W. H. JaCkson, M.A., Assistant Lecturer in Mathematics in the University of Manchester*.

A $S$ a result of some experiments on the method of transmission of the excited activity of radium, Mr. Makower has arrived at the following hypothesis:-The molecules of excited activity, initially uncharged, are projected from radium emanation with velocities large compared with those of gas molecules, and at a certain percentage of encounters with the gas molecules a negative electron is shot off, leaving the activity positively charged.

It gives additional force to his argument to further show that the deviation of the experimental results obtained by him from those required by the above theory are actually less than the errors of observation.

Since the number of ions present in a gas ionized by a small quantity of radium emanation is exceedingly small compared with the number of molecules of gas, it is safe on this view, even though the positive ion influences a much larger field of force than an ordinary molecule, to assume that the importance of encounters with positive ions is negligible.

The amount of activity which, in the experiments described by Mr. Makower, is deposited on the eathode, is to be taken proportional to the number of excited activity molecules

* Communirated by the Physical Society. 